\title{
EVALUATION OF DEPEGMENTING AND ANTIERYTHEMIC EFFECTS OF COSMETIC EMULGELS CONTAINING RASPBERRY FRUIT EXTRACT ON HUMAN CHEEK SKIN
}

\author{
RIZWANA KAUSAR ${ }^{1 *}$, NAVEED AKHTAR ${ }^{1}$ \\ ${ }^{1}$ Faculty of Pharmacy and Alternative Medicine, the Islamia University of Bahawalpur, Punjab, Pakistan \\ Email: rizvi_awan@yahoo.com
}

Received: 09 Sep 2016 Revised and Accepted: 23 Nov 2016

\begin{abstract}
Objective: This research work was performed to discover the efficacy of newly formulated topical formulation (o/w) emulgel of Raspberry fruit extract against its base taken as a control on skin erythema and skin melanin.

Methods: Concentrated Raspberry fruit extract was prepared by macerating fresh fruit in aqueous methanol under room temperature. This extract was then entrapped in the inner oily phase of o/w emulgel. Newly formulated, formerly evaluated base (without extract) and a formulation containing 4\% concentrated extract of Raspberry were applied to cheeks of 13 healthy female human volunteers for a period of 12 w. Skin erythma and melanin were measured after every two weeks to evaluate any effect produced by this topical formulation.

Results: Base showed insignificant $(\mathrm{p} \geq 0.05)$ while formulation showed a significant decrease in skin erythma. Skin melanin content was insignificantly decreased by base but significantly decreased by the formulation. The newly developed cosmetic emulgel of Raspberry fruit extract
\end{abstract} showed its effects without causing any irritation and was found to be suitable and safe dermatological formulation.

Conclusion: Formulation was successfully evaluated for its dermatological effects. It was found to be a useful, harmless and cost effective skin whitening treatment derived from natural sources.

Keywords: Raspberry, Extract, Anti-erythemic, Depegmentation, Emulgel, Mexameter, Anova

(C) 2017 The Authors. Published by Innovare Academic Sciences Pvt Ltd. This is an open access article under the CC BY license (http://creativecommons.org/licenses/by/4. 0/) DOI: http://dx.doi.org/10.22159/ijpps.2017v9i1.15123

\section{INTRODUCTION}

Skin is a vital organ for non-invasive topical drug delivery. Topical drug delivery vehicles (emulgels, gels) and transdermal patches can improve patient compliance due to decrease in the dosage frequency [1]. Naturally, derived products have always found to be a potential source for biologically active drugs used in phytocosmetics [2]. Important bioactive phytochemical constituents include flavonoids, alkaloids, essential oils, phenolics, tannins and saponins [3]. In the recent era, phenolic constituents have gained marked attention due to their use in skin care products for the treatment of acne, dryness, eczema, freeradical scavenging, aging, inflammation and skin protection [4].

Hyperpigmentation is one of the most common facial disorders. It has been observed from various studies, that a local increase in melanin formation or uneven distribution of melanin can cause local hyperpigmentation or spots. Whitening agents such as hydroquinone, kojic acid or arbutin are widely used in cosmetic products as active ingredients [5]. Plant-derived extracts that have an excellent inhibitory effect on melanin synthesis may be a good choice for whitening of skin and protection against skin darkening $[6,7]$. Accumulation of abnormal quantity of melanin in different parts of the skin may result in pigmented skin spots, which can become an esthetic problem $[8,9]$.

Red Raspberry, which belongs to genus Rubus L. of family Rasaceae, is a kind of berry with tender and juicy fruits. Fruits of red Raspberry are rich in vitamins and minerals and especially abundant in anti-cancer, anti-aging substances such as gallogen $[10,11]$, therefore famous as "Fruit of Life" in the United States. It is a good source of antioxidants that have gained great importance in our routine life [12, 13]. In addition, Raspberry fruits contain a significant amount of flavonoids. It was reported in the literature that flavonoids could remove $\mathrm{O}_{2}$-in human bodies, strengthen the immune system, improve blood flow and decrease blood pressure [14]. The aim of this study was to formulate a new cosmetic o/w emulgel of Raspberry fruit extract and evaluate it for its effects on various skin related parameters, like reduction in skin erythema, skin melanin and compared it with base (without extract) taken as control.

\section{MATERIALS AND METHODS}

\section{Chemicals and reagents}

Methanol (analytical grade), Paraffin oil (Merck KGaA Darmstadt, Germany), propylene glycol (Merck KGaA Darmstadt, Germany), Methylparaben (Merck KGaA Darmstadt, Germany), carbopol gel 940, tween 20and span 20 (Merck KGaA Darmstadt, Germany). Distilled water (prepared at Department of Pharmacy, The Islamia University of Bahawalpur, Pakistan).

\section{Apparatus}

Homogenizer (Euro-Star, IKA D 230, Germany), pH-meter (WTW pH-197i, Germany), rotary evaporator (Eyela, Co. Ltd. Japan), water bath (HH. S 21 4. China), electrical balance (Precisa BJ-210, Switzerland), Mexameter® MPA 5 (Courage+Khazaka, Germany).

\section{Plant material}

The Raspberry fruit was purchased from Metro cash and carry store, Islamabad, and was identified by Department of Biological Sciences, University of Sargodha, with Voucher No. Rizwana-6028 and was deposited in the Laboratory of Biosystematics and Medicinal Plants, Department of Botany, University of Sargodha, Sargodha, for future research reference.

\section{Preparation of fruit extract}

$500 \mathrm{~g}$ of fresh fruit was grinded to form a paste, which was then soaked in 70:30 ratio of methanol and distilled water for $72 \mathrm{~h}$. The mixture was filtered through eight layers of muslin cloth and finally through Whatman No. 1 filters paper. The filtrate obtained was passed through the rotary evaporator to get a concentrated extract.

\section{Preparation of cosmetic emulgel}

An o/w emulgel (base as well as active formulation) was prepared by the addition of oily phase to aqueous phase at $75{ }^{\circ} \mathrm{C}$ using homogenizer. The aqueous phase was prepared by heating tween 20 , distilled water, methylparaben and propylene glycol to $75 \pm 1^{\circ} \mathrm{C}$. 
At the same time, oily phase (paraffin oil and span 20) was heated to the same temperature. $4 \%$ fruit extract was added to oil phase and then oily phase was added to aqueous phase drop by drop with continuous stirring to prepare formulation, and no extract was added to oil phase to prepare the base.

$2 \mathrm{~g}$ of carbopol 940 was dispersed in water in (q. s to $100 \mathrm{ml}$ ) with the help of mechanical stirrer at a speed of $1000 \mathrm{rpm}$ until no lump of carbopol left at room temperature. After complete dispersion of carbopol, triethanolamine was added drop by drop and mixed thoroughly, and after each addition, $\mathrm{pH}$ was checked until it reached within range of 5-6.5 which is within the range of skin $\mathrm{pH}[15]$.

Finally, the prepared emulsion was dispersed drop by drop in the prepared gel at $2000 \mathrm{rpm}$ by using homogenizer for $15 \mathrm{~min}$ until an emulsion was added completely. 2-3 drops of fragrance were added to give good aroma to emulgent. After continuous stirring, the speed of homogenizer was reduced to $1000 \mathrm{rpm}$ for a period of $5 \mathrm{~min}$ for homogenization. The speed of the mixer was then further reduced to $500 \mathrm{rpm}$ for further $5 \mathrm{~min}$ until emulgent (base and formulation) cooled at room temperature.

\section{Product evaluation on skin}

After approval from Pharmacy Research Ethics Committee, The Islamia University of Bahawalpur (Ref. No. 66-2015/PREC), a total of 13 healthy female volunteers with a mean age of $25 \mathrm{y}$ were selected, and consent form was signed before beginning of a study from all volunteers. Volunteers were examined by a dermatologist for skin and other diseases.

The experiments were performed on cheeks of volunteers, as cheeks are more susceptible to ultraviolet (UV) radiations. Every volunteer was instructed to apply creams in the morning after face wash and at night on cheeks for the period of $12 \mathrm{w}$ and came for measurement of effects on $2 \mathrm{nd}, 4 \mathrm{th}, 6 \mathrm{th}, 8 \mathrm{th}, 10 \mathrm{th}$ and 12 th week in the morning at 10 a. m. The effects were measured by using Mexameter ${ }^{\circledR}$ MPA 5 (Courage+Khazaka, Germany). They were instructed to wash their faces with water and sit, to become normal with the environment for 30 min before any measurements were taken. Values for skin parameters were taken at controlled room temperature of $25 \pm 1{ }^{\circ} \mathrm{C}$.

\section{Evaluation of skin compatibility by patch test}

To evaluate skin compatibility with the formulation, patch test was performed on both forearms of each volunteer on the first day of skin testing. A $5 \times 4 \mathrm{~cm}$ region was marked on forearms. Patch for left forearm was saturated with $1.0 \mathrm{~g}$ of formulation while the patch for right forearm was saturated with $1.0 \mathrm{~g}$ of the base. Each was applied to marked regions separately on each forearm. The regions were covered with surgical dressing after application. Patches were removed after $48 \mathrm{~h}$ and forearms were washed with physiological saline and skin was observed for any irritation [16].

\section{Panel test}

Every volunteer was provided with a questionnaire, designed previously to test sensory values of products. This questionnaire consisted of seven parameters to be assessed and every parameter was assigned 11 values from -5 to +5 , indicating very bad to very good respectively. The parameters were 1 ; ease of application, 2; spreadability, 3; sense just after application, 4; the sense in the long term, 5; irritation, 6; shine on skin, 7; a sense of softness.

\section{Ethical standards}

The approval of this study (Ref. No. 66-2015/PREC) was taken from the Board of the Advanced Study and Research (BASAR), the Islamia University of Bahawalpur and the Institutional Ethical Committee, Faculty of Pharmacy and Alternative medicine, The Islamia University of Bahawalpur, Pakistan.

\section{Mathematical analysis}

The percentage changes for the each value of different parameters of volunteers were determined by the following formula:

$$
\mathrm{P}=[(\mathrm{A}-\mathrm{B}) / \mathrm{B}] \times 100
$$

Where;

\section{$\mathrm{P}=$ Percentage change}

$\mathrm{A}=$ Individual value of any parameter of $2 \mathrm{nd}, 4 \mathrm{th}, 6 \mathrm{th}, 8 \mathrm{th}, 10 \mathrm{th}$ or 12th week

$\mathrm{B}=$ Zero hour value of that parameter.

\section{RESULTS AND DISCUSSION}

\section{Skin melanin content}

Skin melanin was measured by Mexameter® MPA 5 (Courage +Khazaka, Germany), at regular intervals of 2nd, 4th, 6th, 8th, 10th and 12th week and percentage of changes have been presented in fig. 1 .

\section{Skin erythema}

Skin melanin was measured by Mexameter ${ }^{\circledR}$ MPA 5 (Courage+Khazaka, Germany) at regular intervals of 2nd, 4th, 6th, 8 th, 10 th and 12 th week and percentage of changes have been presented in fig. 2.

\section{Skin melanin content}

In this research work, it was observed that there was an increase in skin melanin values after the application of base but in the case of application of formulation there was a gradual decrease in skin melanin content throughout the $12 \mathrm{w}$ of the study period. With the application of ANOVA test, it was found that there was an insignificant $\rho \geq 0.05$ effect of base with respect to time while in case of active formulation it was evident that melanin content was significantly $\rho \leq 0.05$ reduced with respect to time. Melanin is pigment which plays a very important role for color of skin in humans. Tyrosinase enzyme is known to be the basic enzyme in melanin formation [17]. Over-activity of this enzyme leads to large production of melanin pigment leading to hyper-pigmentation of the skin and its under-activity leads to depigmentation. The decrease in skin melanin contents can be related to the phenolic and flavonoids compounds present in Raspberry which include quercetin, isoquercetin, quercetin-diglycoside, dihydroxykaemnipferolglycoside, caffeic acid, rosmarinic acid, rutin, carnosic acid, catechol derivatives [18]. The tyrosinase inhibition activity attributed to flavonoids might be due to chelating the active center of tyrosinase enzyme which leads to reduced melanin contents synthesis [19].

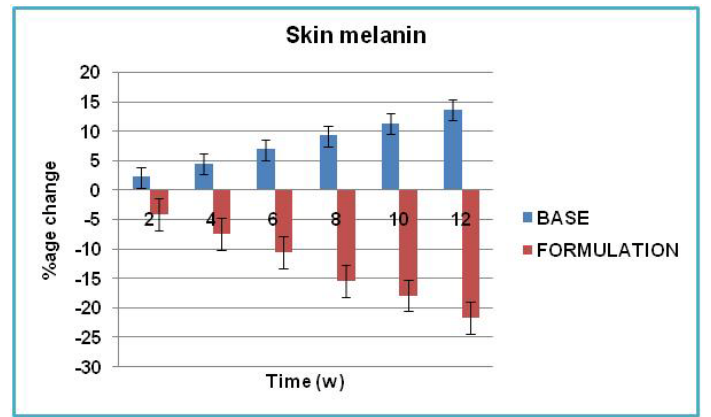

Fig. 1: Percentage of change in skin melanin of 13 volunteers after application of base and formulation

\section{Skin erythema}

Formulations developed for topical applications must not produce any irritation or redness. To assess this, patch test was carried out which indicated that base has slight redness, but formulation did not exert any mark of redness. In this research work, it was observed that after applying ANOVA test, there was an insignificant $(\rho \geq 0.05)$ effect of the base with respect to time. In the case of active formulation, it was evident that erythema was significantly ( $\rho \leq$ 0.05 ) reduced with respect to time. It was also observed that there was a slight increase in values of erythema of skin throughout study period after application of base. However, after application of formulation erythema contents were decreased. The decrease in 
skin erythema indicated that formulation was very effective to soothe the skin and harmless to cause any irritation. Destruction of DNA, proteins and cellular lipids by free radicals are considered to be responsible for erythema. $\beta$ carotene and tocopherols are effective as free radical scavengers[20]. The Raspberry fruit has sufficient amount of tocopherols (vitamin E) so it is very effective to reduce skin erythema.

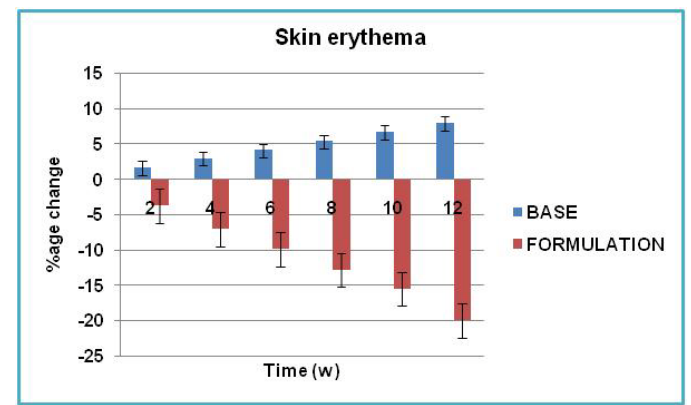

Fig. 2: Percentage of change in skin erythema of 13 volunteers after application of base and formulation

\section{CONCLUSION}

From the present findings, it has been concluded that a stable and effective topical o/w cosmetic emulgent containing Raspberry fruit extract produce skin whitening properties because it effectively reduces skin melanin production when applied topically. In the case of erythema study, a reduction in skin erythema/redness by formulation can be attributed to anti-inflammatory effects of Raspberry fruit extract. The formulation had no harmful effects on skin and can be useful and cost-effective natural skin whitening treatment. A targeted study can be designed in future, in patients with the problem of freckles and melasma to explore the full potential of this fruit.

\section{ACKNOWLEDGEMENT}

The authors wish to thank Higher Education Commission and Dean of the Faculty of Pharmacy and Alternative Medicine, The Islamia University of Bahawalpur, Pakistan for the financial and moral support.

\section{CONFLICT OF INTERESTS}

Declared none

\section{REFERENCES}

1. Lakshmi P, MK Kumar, A Sridharan, S Bhaskaran. Formulation and evaluation of ibuprofen topical gel: a novel approach for penetration enhancement. Int J Appl Pharm 2011;3:25-30.

2. Alqasoumi SI, MS Al-Dosari, AM AlSheikh, MS Abdel-Kader. Evaluation of the hepatoprotective effect of Fumaria parviflora and Momordica balsamina from Saudi folk medicine against experimentally induced liver injury in rats. Res J Med Plant 2009;3:9-15.
3. Krishnaiah D, T Devi, A Bono, R Sarbatly. Studies on phytochemical constituents of six Malaysian medicinal plants. J Med Plants Res 2009;3:67-72.

4. Aburjai T, FM Natsheh. Plants used in cosmetics. Phytother Res 2003;17:987-1000.

5. Petit L, G Pierard. Skin-lightening products revisited. Int J Cosmet Sci 2003;25:169-81.

6. Baurin N, E Arnoult, T Scior, Q Do, P Bernard. Preliminary screening of some tropical plants for anti-tyrosinase activity. J Ethnopharmacol 2002;82:155-8.

7. Bernard P, J Berthon. Resveratrol: an original mechanism on tyrosinase inhibition. Int J Cosmet Sci 2000;22:219-26.

8. Chang TS. An updated review of tyrosinase inhibitors. Int J Mol Sci 2009;10:2440-75.

9. Lin VCH, HY Ding, SY Kuo, LW Chin, JY Wu, TS Chang. Evaluation of in vitro and in vivo depigmenting activity of raspberry ketone from Rheum Officinale. Int J Mol Sci 2011;12:4819-35.

10. Häkkinen SH, SO Kärenlampi, HM Mykkänen, IM Heinonen, AR Törrönen. Ellagic acid content in berries: influence of domestic processing and storage. Eur Food Res Technol 2000;212:75-80.

11. Puupponen-Pimiä R, L Nohynek, HL Alakomi, KM OksmanCaldentey. Bioactive berry compounds-novel tools against human pathogens. Appl Microbiol Biotechnol 2005;67:8-18.

12. Dontha S. A review of antioxidant methods. Asian J Pharm Clin Res 2016;9(Suppl 2):14-32.

13. Fidrianny I, Choirunnisa AR, K Ruslan. Comparison of five antioxidant assays for estimating antioxidant capacity from three Solanum sp. extracts. Asian J Pharm Clin Res 2016;26:123-8.

14. Fang P. Biological effects of flavones. J Dali Med College 1998; 7:52-4

15. Narendran H, S Koorapati, L Mamidibathula. Formulation and evaluation of aceclofenac-lycopene trans emulged. World J of Pharm Res 2013;2:1036-45.

16. Hachem JP, K De Paepe, E Vanpee, L Kaufman, V Rogiers, D Roseeuw. The effect of two moisturisers on skin barrier damage in allergic contact dermatitis. Eur J Dermatol 2001;12:136-8.

17. Rasul A, N Akhtar, BA Khan, T Mahmood, S uz Zaman, A Ali, et al., Evaluation for antiarrhythmic and depigmenting effects of a newly formulated emulsion containing basil extract. J Med Plants Res 2011;5:6249-53.

18. Jayasinghe C, N Gotoh, T Aoki, S Wada. Phenolics composition and antioxidant activity of sweet basil (Ocimum basilicum L.). J Agric Food Chem 2003;51:4442-9.

19. Saewan N, S Koysomboon, K Chantrapromma. Anti-tyrosinase and anti-cancer activities of flavonoids from Blumea balsamifera DC. J Med Plants Res 2011;5:1018-25.

20. Stahl W. Carotenoids and carotenoids plus vitamin E protect against ultraviolet light-induced erythema in humans. Am J Clin Nutr 2000;71:795-8.

\section{How to cite this article}

- $\quad$ Rizwana Kausar, Naveed Akhtar. Evaluation of depegmenting and antierythemic effects of cosmetic emulgels containing raspberry fruit extract on human cheek skin. Int J Pharm Pharm Sci 2017;9(1):236-238. 